\title{
Employees' Working Life and Performance of UK Ethnic Minority Restaurants: A Qualitative Approach
}

\author{
BM Razzak, Robert Blackburn and George Saridakis
}

\begin{abstract}
Purpose

This paper investigates the linking between employees' working life (EWL) and job performance of ethnic minority Bangladeshi restaurants in Greater London.

\section{Design/methodology/approach}

We use in depth face-to-face interviews of 40 participants working in 20 Bangladeshi restaurants (BRs) following a convenience sampling method. A thematic analysis technique, with the help of QSR N10, developed two key themes related to EWL and performance.
\end{abstract}

\section{Findings}

These themes highlight several aspects of the relationship between EWL and performance. First, EWL is 'beyond' the UK tradition; employers show a domineering attitude; however, employees continue to work due to lack of skills and competence. Second, employees perceive and present themselves as satisfied; however, this satisfaction is not reflected in the business performance of BRs. Third, the analysis shows that business owners 'trap strategy' constrains employees to develop their skills for mobility to other industries. Hence, employees' express satisfaction with their existing situation on the basis that it is the best they can hope for, given their specific skills and competence, and need for some security in the UK. Fourth, non-financial performance, for example, job autonomy, sense of fulfilment is related to $E W L$.

\section{Practical implications}

The paper provides a framework to promote a better understanding of the linking between employees' working life and performance of $U K$ ethnic minority restaurants. Also, the paper makes recommendations for further research, including an examination of the applicability of the findings to SMEs operated by other ethnic groups in the UK.

\section{Originality/value}

This paper adds to the scarce literature on the working life of people in Bangladeshi restaurant businesses in the UK and the relationship between EWL and business performance.

Keywords: employee working life, performance, job satisfaction, Bangladeshi restaurants, thematic analysis. 


\section{Introduction}

This paper analyses the relationship between employees working life (EWL) and business performance in small and medium-sized enterprises (SMEs). EWL is regarded as a strong determinant of an individual's life satisfaction (e.g. Judge and Watanabe, 1993; Sivapragasam and Raya, 2014; Alrawadieh et al., 2020) and an integral part of organisational success (see, for example, Buhai et al., 2008; Lai et al., 2017; Dhamija et al., 2019; Kakkar et al., 2019; Saridakis et al., 2020). EWL includes occupational status, workplace location, hours of work, annual leave, flexible working arrangements, fringe benefits and pay (e.g., Truss et al., 2006). EWL also encompasses job satisfaction (JS), working environment, organisational culture and management attitude. The literature suggests that good EWL practices include a flexible and supportive work environment, enabling employees to focus on their work while at work. EWL has been found to have a direct impact on business growth, development and survival (Messersmith et al., 2018; Dhir and Shukla, 2019; Allam and Shalik, 2020). Consequently, employers tend to invest in professional development practices to attract and develop talent through the enhancement of EWL (Budhwar et al., 2019).

Although EWL is important in all organizations, it could be argued that it is of paramount importance in smaller enterprises because of their high reliance on people (Harney and Alkhalaf, 2020). However, the working conditions of smaller enterprises have been found to be inconsistent and variable. Wilkinson (1999) depicts EWL in small firms into two polar types. First, is the 'small is beautiful' scenario where the size of enterprise facilitates close and harmonious working relationships; and a second, the 'bleak house' scenario, in which the small firm is dictatorially run, with employees under close supervision and suffering poor working conditions. It has been argued that the variations in the internal conditions is associated with the context of the enterprise, its size, sector, and external market relationships (Rainnie, 1989; McGaughey et al., 2005; Harley and Alkhalaf, 2020; Lewis et al., 2020). Others point out the significance of 'agency', that is the objectives of owner-managers and their workforce which in combination with the firm's context, lead to a negotiated order of employment conditions within the enterprise (Ram et al., 2007; Pedaci and Betti, 2020). Yet, how the internal working life of employees is shaped and linked to firm performance remains relatively unexplored in SMEs.

The aim of this paper is to investigate the EWL and performance of UK ethnic minority restaurants owned and managed by Bangladeshi entrepreneurs. This focus provides an interesting lens to explore the factors that shape EWL and its relationship with enterprise performance. Bangladeshi owned SMEs have a long history in the UK, with a particular 
success in the restaurants (Alexander et al., 2020). The majority of so-called 'Indian Restaurants' in the UK are Bangladeshi-owned. In 1946, there were an estimated 20 restaurants or small cafes owned by Bangladeshis; in 1960 there were 300; and by 1980, more than 3,000 (Gillan, 2002; Wilson, 2017). By 2002, there were 8,500 curry restaurants, of which roughly 7,200 were Bangladeshi (Gillan, 2002). Clearly, the Bangladeshi SME sector has grown progressively over the last few decades to approximately 10,500 restaurants, employing more than 90,000 people in the UK (mostly of Bangladeshi origin), and with an estimated annual turnover of $£ 3.5$ billion (Khandaker, 2016). Bangladeshi SMEs play a particularly important role in greater London, with more than 2,500 restaurants (Khandaker, 2016). Thus, the Bangladeshi community has thrived in the United Kingdom, and third generation Bangladeshis are on their way to establishing themselves in the mainstream British business environment. They have, as a result, generated considerable interest among academics, practitioners, and policy-makers. This paper aims to shed light on the factors that contribute to EWL in ethnic minority restaurants owned by Bangladeshis and how EWL, in turn, is related to financial and non-financial performance.

The paper is organised as follows. Section 2 presents the existing literature on EWL and SME performance. Section 3 discussed the data and methodology. Section 4 discusses the findings. The final section 5 concludes the paper.

\section{Literature review}

In the UK, the ethnic minority business population is predominated by South Asians and until recently, grew rapidly (Ram and Jones, 2008; Haq, 2015). In the restaurant sector, employees normally maintain long-term relationships based on trust and ties of kinship and recommendations from others within the same ethnic group network (Bloch and McKay, 2015). Bullying and poor career prospects and training, however, may result in lowering employees' JS and commitment and increasing the intention to leave the job (e.g. Mathisen et al., 2008; Jung and Yoon, 2019). Vacillations in the external environment may also add pressures to the sector putting at risk the survivability of these businesses and deteriorating the working conditions in which employees of this sector operate.

Employee well-being is vital within all organisational contexts as it is significantly related to EWL and performance. Employee well-being is connected to various performance, for example, productivity, employee turnover, and work-life balance (Bakker and Oerlemans, 2011; Bozionelos and Singh, 2017; Deloitte, 2017; Keeman et al., 2017). Singh et al. (2019a) 
indicated that the positive relationship between self-efficacy and workplace well-being (see also Singh et al., 2019b). Performance not only depends on both financial and non-financial support such as job autonomy and work-life balance. Walker and Brown (2004) highlight that the non-financial measures of success for owner-managers include employee autonomy, a sense of fulfilment and the ability to balance work and family life.

In this section, the review focuses on three key issues. First, we explain the distribution of firm size. Second, we discuss the existing body of knowledge of EWL. Third, we present the existing literature on firm performance focusing particularly on the importance of nonfinancial performance. These relatively un-researched aspects in the restaurant sector (Gillan, 2002; Ram and Jones, 2008) are even more critical given the current circumstances in which EWL may act as an important factor in fostering resilience and improving performance in the restaurant sector.

\subsection{The significance of small firms and the sample size distribution}

Macro data shows that the size-distribution of enterprises in most economies is heavily skewed towards SMEs. Official data for the UK (BIS, 2020) reports that there is an estimated 6 million private sector enterprises in 2020, of which 5.94 million were small businesses, employing less than 50 people ( $99.3 \%$ of the total business population). However, if we exclude those without employees the total number of enterprises drops to a total of 1.4 million employers, of which 1.37 million are small firms (1-49 employees; 1.12 million are micro (1-9 employees)), and only 7,835 are large firms (250+ employees) (BIS, 2020: Table A).

The sample of firms for this research comprise Bangladeshi-owned UK restaurants. The data is drawn from 40 interviews with respondents from 20 enterprises. Overall, 18 of the firms are small and two are medium sized. They have an average of five employees. The interview participants consist of employees and/or managers, depending on the structure of the enterprise. However, the small size of the enterprises means that there is no specialist human resource function in these restaurants (see discussion by Storey et al., 2010). Instead, owner-managers and managers are found to be multi-tasking rather than having specialist functions and part of their role is to manage their employees, the jobs they do and set their pay and conditions. What distinguishes these firms from many others, including the catering industry, is the importance of faith, kinship and family ties across in Bangladeshi restaurants, potentially adding a further significant influence on EWL. 


\subsection{EWL related factors: size, sector and ethnicity context}

EWL comprises a range of influences including, the pay and conditions of employees, where they work, hours of work, annual leave and flexible working arrangements (Truss et al., 2006). Laar et al. (2007) show that EWL is also shaped by career opportunities and general well-being. However, EWL also encompasses job autonomy and self-governing opportunities (Vliet and Hellgren, 2002). Differences in EWL can, on the one hand, lead to employee 'burnout' or on the other, greater engagement (Maslach et al., 2001; Jung and Yoon, 2019; Gupta et al., 2019). A poor work-life balance, such as long working hours are detrimental to employees' health and can subsequently result in lower levels of job performance (see Truss et al. 2006; Burke and McAteer, 2007).

The catering industry is particularly demanding on its staff and noted for the long working hours of workers. Wright and Pollert (2006, p. 17), for example, found that:

'Long working hours are typical in hotels and restaurants and were found to be very common among those interviewed. Hardly any of the full-time workers interviewed did less than a 40-hour week, with 50 to 60 hours a week being common for many, particularly those working in restaurants, who often worked late into the evening.'

The industry is also known for its low levels of flexibility and poor levels of compliance in relation to holidays and sick pay. In their discussion of EWL in the restaurant sector overall, Wright and Pollert (2006, p.1 and p. 21, respectively) reported that:

'There was little awareness of holiday and leave entitlements. Very few workers received more than the statutory right to four weeks' holiday. Some reported getting no paid holidays or receiving less than the legal minimum, and there was low awareness of holiday entitlement. In small restaurants, there was sometimes an open policy of two weeks' leave.....Most interviewees, when asked about whether they would get paid if they were off sick, did not know. A small number said that they would be paid for one or two days of sickness, but not more....'

To this sector dimension is also that of size of firm. Dex et al. (2001) examined the role of flexible working arrangements of SMEs as a means of reconciling the pressures in work and domestic life. The idea of 'flexible organisation' is an inherent part of the discourse, embraced by business leaders and researchers. As a result, flexibility in the organisation setting has 
become increasingly attractive and important (Corby and White, 1999; Kalleberg, 2001; Skorstad and Ramsdal, 2009; Sobaih et al., 2011). The literature shows how appropriate levels of working hours are fundamental for a satisfactory EWL. Working time has always been a source of conflict in industrial relations (e.g. Alves et al., 2007; Foy et al., 2019). Dissatisfaction with the job is an important determinant of employee turnover (Leiva et al., 2012) and this is a strong feature of employment in hotels, as shown in the relatively high levels of employee turnover in the sector (Guilding et al., 2014).

To this end, handling high employee turnover is critical for any organisation to stay competitive, as new recruitment incurs opportunity costs, search time and financial redundancy costs as well as potential negative effects on the entrepreneurial behaviour of staff (Liebregts and Stam, 2019). Consequently, a good company has to work on its strategy and mechanisms for addressing high employee turnover and improve employee retention (Anvaria et al., 2013; Saridakis and Cooper, 2016). In one of the first studies of employment satisfaction in small firms, Ingham (1970) argued that the low rates of labour turnover and absenteeism found in small firms were due to high levels of congruence between workers' prior orientations to work and the organisational rewards structure. In other words, they were more likely to emphasise non-pecuniary rewards for working than those in larger enterprises and a strong organisational commitment. Alternatively, Deery and Jago (2008) found that employee turnover was a result of dissatisfaction with the financial benefits and unhealthy physical working conditions in the enterprise. Therefore, effective management practices and reasonable working hours lead to higher levels of EWL; conversely, poor EWL turns to job dissatisfaction which then influences employee turnover (see Saridakis and Cooper, 2016).

Simons and Enz (1995) reported that the three characteristics employees most value from their employer are good wages, job security and opportunities for advancement. This is not only for the benefit of the employee or to generate a harmonious workplace. Employers, owners and managers should be concerned about the well-being of their employees from an instrumental perspective as this as this could be a key underlying factor that impacts upon the performance of an enterprise (Akehurst et al., 2009; Naseem et al., 2011; Ogunyomi and Bruning 2016).

Moreover, the quality of EWL of Bangladeshis in the UK should also take into consideration contextual influences other than the workplace, including their religion and culture (Alexander et al., 2020). A key issue to be addressed is the relative detachment of females from the workplace. Basu and Altinay (2002) indicate that Bangladeshi businesses in the UK are influenced by religion and family tradition, especially when it comes to women's 
participation in business. Similarly, Ram et al. (2000) point out that there are 'religio-cultural' reasons for the absence of Bangladeshi women from formal participation in business. Hence, a combination of tradition and modern prejudice keeps women out of restaurant work and maintains a set-up in which the male's role is to provide income for the family and the female's is restricted to domestic work and taking care of children, allowing little time for a job. Hence, the literature demonstrates that business practices are profoundly influenced by cultural factors unique to different ethnic groups, including norms, behaviours, beliefs and customs (Wright and Pollert, 2006). This distinctiveness is important as it influences the EWL of employees in Bangladeshi restaurants and need for attention on its distinctiveness from mainstream literature.

In addition to the factors discussed above when setting the scene for EWL in Bangladeshi restaurants, is that of the condition of the Bangladeshi restaurant sector. UK based Bangladeshi restaurants are currently encountering a crisis (Alexander et al., 2020). This appears to be related to changes in the labour market and the composition of the Bangladeshi UK population as well as changes in consumer tastes. Wilson (2017) found that thousands of Bangladeshi restaurants are short of staff to cook the food, and customers to eat it. Across the industry, two or three curry houses per week are closing down, and hundreds of established restaurants face closure because of an acute shortage of chefs (Birrell, 2015; Witts, 2015; McFadyen, 2015; Khandaker, 2016; Lomas-Farley, 2016; Wilson, 2017). This shrinkage has an adverse impact on existing restaurant employees who are increasingly complaining of mental stress following business failure (Wilson, 2017). It also puts a downward pressure on rates of pay. Employees effectively consent to work under poor terms and conditions and whether they are satisfied or not (Wilson, 2017). Although this goes beyond the scope of this paper, COVID-19 and the measures associated with it such as lockdown and social distancing can have a detrimental impact on these businesses and their employees' wellbeing (e.g. Khan, 2020; Yang et al., 2021; Shanker et al., 2021; Tuzovic and Kabadayi, 2021).

\subsection{Financial/non-financial performance: linking EWL with performance}

The success of organisations is conventionally measured by financial and non-financial criteria (Walker and Brown 2004; Angel et al., 2018; Singh and Singh, 2019). This includes the number of employees of the organisation or financial performance, for example, its profit, turnover or return on investment. Non-financial measures of success include employees' autonomy, JS and the ability to balance work and family responsibilities (e.g. Han et al., 2017; Shih et al., 2019). For small firms, measures of success are multi-faceted, often embedded in the ambition of the 
owner-manager and monetary rewards are only one possible factor (Wach et al., 2016). Walker and Brown (2004) argue that financial criteria are considered to be the most appropriate measure of business success, even though many small business owners are motivated to start a business by personal factors. Gray et al. (2012) indicate that the key to success for businesses is financial success such as constant cash flow, although this does not permit drawing money from the business too quickly. It is based on repeatability of business to achieve recurring revenues, growth, the maintenance of cash flow, and increased shareholder value, while nonfinancial measures of success include a sense of fulfilment or challenge, or building a life-style business and work-life balance. Angel et al. (2019) suggest that how entrepreneurs define success has implications for how they go about developing their firms, as well as for their individual well-being. Hence, the performance of the enterprise is linked to the working life of those working within it, including the owner-manager.

Lin (1998) finds that the key success factors of SMEs are 1) that 'people-related' issues are more emphasised over 'structure' and 'technology'; 2) the business founders' management skills, customer focus, and resource creation are more important than their technical skills; and 3) companies show more concern for 'soft' attitudes, skills and operating methods. Simpson et al. (2004) find that there is a range of criteria associated with the success in terms of individual owner characteristics, organisational values and performance measures. This is supported by Angel et al. (2019). Blackburn et al. (2013) agree that owner-manager characteristics and business style are important for organisational performance. Boonlua and Aditto (2013) show that there are several factors affecting the success of SMEs, including government, business, technical, social and global factors. Moreover, Mahrouq (2010) suggests five success factors of business: technology, the structure of the firm, financial structure, productivity, and HR management.

Sheehan (2014) finds that the use of human resource practices in SMEs positively enhance sustained competitive advantage. To this end, Connell and Hannif (2009) and Naseem et al. (2011) argue that the level of employee satisfaction not only enhances productivity but also increases the quality of work. Conversely, problems of job dissatisfaction are a threat to the success of the business. Employees with poor JS tend to have higher rates of absenteeism, poor performance and a higher tendency to leave the job (Bozeman and Gaughan, 2011; Kakkar et al., 2019; Olugbade and Karatepe, 2019). An increased absenteeism and higher turnover can have a negative effect on the profit of a company, and so become a barrier to performance. Consequently, employers, owners and managers have been encouraged to be concerned about 
the well-being of their employees, as it could be the key underlying factor to the performance of an enterprise (Akehurst et al., 2009; Kansas State University, 2009; Naseem et al., 2011; Saridakis et al., 2013; Tang and Lee, 2014).

Our paper aims to examine the link between EWL and performance in UK ethnic minority restaurants and contribute to the understanding of the British restaurants (BR) of Bangladeshi origin.

\section{Data and methodology}

\subsection{Data}

The sample firms for this paper are from UK restaurants that are owned by Bangladeshis in Greater London. This is a context in which the sector has undergone contraction but at the same time continues to struggle to attract high-quality staff and chefs (Alexander et al., 2020). The paper considers 20 enterprises that have minimum of five employees (e.g. the 2004 WERS) and maximum employees 49, and selects two interviewees from each enterprise, giving a sample size of 40 (see Table 1). We use a convenience sample, which was selected purposively for this research. Convenience sampling method is thus one of the most widely used sampling strategies (Pajo et al., 2010; Robson, 2011; Hasle et al., 2012). ${ }^{1}$ The interviews were conducted in 2016.

Table 1. Categories of participants.

\begin{tabular}{|l|c|c|c|}
\hline Job Position & No. of interviews & $\boldsymbol{\%}$ & $\begin{array}{c}\text { Average (mean) } \\
\text { age }\end{array}$ \\
\hline Manager & 10 & 25 & 45 \\
\hline Assistant Manager & 3 & 8 & 40 \\
\hline Chef & 5 & 12 & 50 \\
\hline Waiter and Stock Delivery & 20 & 50 & 35 \\
\hline Kitchen Assistant & 2 & 5 & 30 \\
\hline Total & $\mathbf{4 0}$ & $\mathbf{1 0 0}$ & $\mathbf{4 0}$ \\
\hline
\end{tabular}

Note: Most of the respondents were men (97\%); hence, the gender variable was excluded from our analysis.

\footnotetext{
1 To the lesser extent, we also used secondary data to pursue its objectives, for example, publications of Bangladesh Caterers Association, Department for Business, Innovation and Skills (BIS) and Department of Trade Industry (DTI) of EWL of SMEs in the UK.
} 
Restaurant staff are usually divided into two sections, 'front side' and 'kitchen side': conventionally known as front of house and back of house. The front side include a manager, assistant manager and waiters. On the other hand, the kitchen side includes chefs, chef assistants and kitchen assistants. Both sections are monitored and managed by the restaurant manager. For this study, the participants are classified based on their job or position, being one of a) manager b) assistant manager c) chef d) waiter and stock delivery and e) kitchen assistant. In the selection of participants, researchers ensured that all groups of the employees were represented so that researchers could establish research findings. The distribution of participants is shown in Table 1. The participants are presented anonymously in the findings and discussion sections (i.e. their names have been changed).

\subsection{Research method}

The interview participants comprised employees and managers, depending on the structure of the enterprise. Interviews were undertaken face-to-face and followed a semi-structured questionnaire that was designed to allow flexibility and flow in the interview, whilst collecting detailed information on the enterprise. This included open and closed questions. Overall, the study employs an inductive approach because there was no requirement for pre-determined theory to collect data and information (see Bryman and Bell, 2011). Saunders et al. (2009) state that an inductive approach involves the development of a theory as a result of the observation of empirical data, while the deductive research approach allows the research to establish a hypothesis by using theory. For this research, we use the thematic analysis technique (see Braun and Clarke, 2006; Quinlan, 2011) using QSR N10 tool for data analysis. Through this analytical procedure two key themes emerged:

Theme 1: UKBRs employees' working life is beyond the UK tradition.

Theme 2: Restaurants' performance both financial and non-financial is in a slump.

\section{Findings and discussion}

This section presents two empirical models, which articulate based on research objectives. Each model identified some issues of BRs sector in the UK. These issues are discussed with the link to primary and secondary data. 


\subsection{Model 1: UKBRs employees' working life}

Based on the thematic analysis, this study develops the first model titled as UKBRs' employees' working life. Figure 1 identifies the key elements of EWL in UKBRs. It shows that in most of the cases examined, the study found unfair practices that disadvantaged and deprived workers.

Figure 1. UKBRs' employee working life.

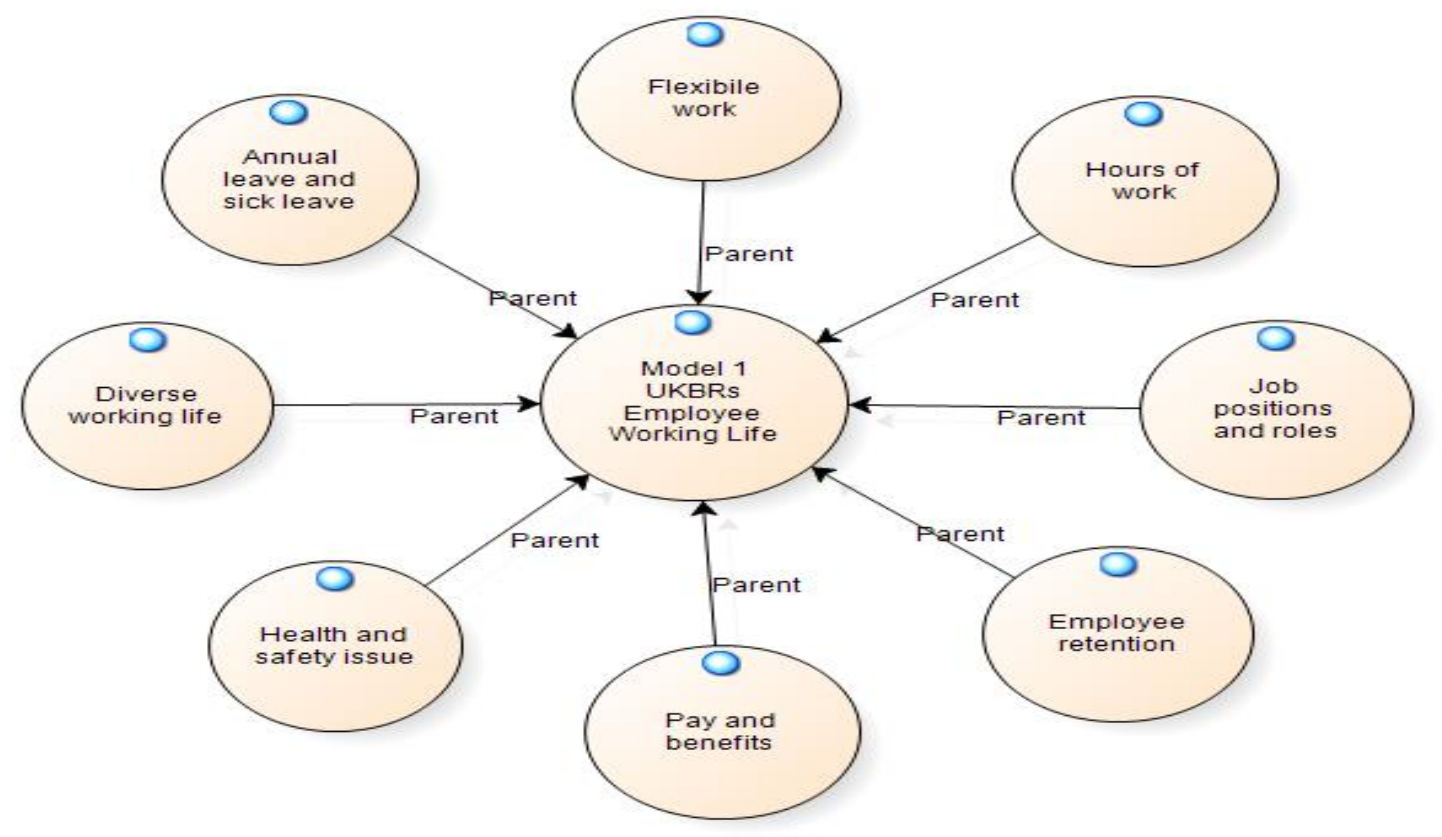

\subsubsection{Diverse working life}

We found that employees of UKBRs show a deep affection towards Bangladeshi food and culture and meet frequently within their local communities. One of the characteristics of many BRs is that most of their customers dine frequently at local restaurants and enjoy Bangladeshi culture in the restaurant and have good relationships with restaurant staff. However, this conviviality was not reflected by all restaurant staff. For many workers interviewed, their working life in the restaurant was comparable to 'slavery' (i.e. absent of basic rights) because they are forced to work split shifts (for example, a shift from 11.00a.m.-2.00p.m. and evening shift of 5.00p.m.-11.00p.m.), with remuneration below the national minimum wage (NMW), limited job security, vague health and safety conditions, and without good management development policies and practices. A respondent replied that his restaurant working life: 
'I do not like working in this restaurant. The owner did not adopt any government law such as health and safety, training and promotion. So, I am not happy, and I do not like this job. ' (Nasir, R31, BR16, Waiter)

\subsubsection{Annual leave and sick leave}

Annual leave or holiday is of concern for many restaurant owners but whether this converted into practice is debatable. Most employees understood that they are entitled to a one-week holiday after six months, which means they can take two weeks holidays in a year, paid or unpaid. Whether or not they can take this time off appeared to depend on the owner's discretion. Kamal (R02, BR01), a waiter from a restaurant stated that:

'We get annual leave, paid or unpaid leave depends on the owner's decision.

I have not yet had any holiday but after six months I will get a one-week holiday, and I heard it is a paid holiday.' (Kamal, R02, BR01, Waiter)

Also, one of the respondents named Lalu (R03, BR02), a manager of a restaurant in London, explained of sick leave opportunity as:

'I get two weeks' holiday which is a paid holiday. But if I do not take my holiday, I will get paid. I am not eligible for sick pay.' Lalu (R03, BR02, Manager)

\subsubsection{Flexible work}

Job flexibility has been frequently identified as a key human resource policy goal, along with strategic intention, quality, and employee commitment, to ensure a flexible organisation structure (Guest 2004). Atkinson's (1984) 'flexible firm model' suggests that organisational flexibility might be enhanced through functional flexibility, numerical flexibility, or a combination of functional and numerical flexibility. Thus, flexibility in the organisation setting has become increasingly important as a labour management instrument (Kalleberg, 2001; Skorstad and Ramsdal, 2009; Van Landuyt et al., 2017).

In practice, this raised the issue of flexibility for who: employees or employer? Whilst many employees where frequently asked to work overtime and long hours, their ability to secure additional time away from work was restricted for fear of pay reductions or at worst job loss. The research also found inconsistencies in treatment by management. Although work flexibility in the UKBRs is limited, some key workers appeared to enjoy more flexible work 
arrangements if they had a good inter-personal relationship with manager or owner. Thus, although a small proportion of employees in the UKBRs enjoy a limited degree of flexibility, for most workers in UKBRs, the lack of flexibility is a cause for dissatisfaction.

\subsubsection{Hours of work}

Long shift hours are common in UKBRs to the point of being the norm. For example, some reported working shifts of 11-12 hours a day and 6 days a week, which add up to 66-72 hours per week. A kitchen assistant in a restaurant says:

'Each shift is 9 hours long, so weekly I work 54 hours. Most of the time I stay in the kitchen and help the chef as an assistant. 54 hours in a week is so tough, but my options are limited. I stay in this job because I have to consider my situation and other facilities, but it affects my personal life." (Jafor, R23, BR12, Chef Assistant)

Moreover, Mofhijul (R35, BR19), a head waiter of a BR was stressed due to long shifts and he noted:

'I do 12 hour shifts every day and 60 hours in a week. I serve customers most of the time. Sometimes I find it difficult working long hours, and I am not happy as I get less time to spend with my family. '(Mofhijul, R35, BR19, Waiter)

The research found that one reason that workers can be forced to do split shifts or long shifts is their limited communication skills and lack of transferable technical and educational qualifications. This makes finding jobs elsewhere difficult. Hence, they can be pressured to accept long shifts for fear of losing their jobs. Beyond the problem of low pay and long shifts, those interviewed were expected to work 2 to 3 hours overtime each day. This is unpaid and part of the custom and practice in this business sector. When workers raise the possibility to claim overtime payment, the business owners explain that they are being paid on a daily or weekly basis rather than on an hourly basis.

\subsubsection{Job position and roles}

There is no literature specifically on job position and job structure related to UKBRs. However, this research finds that employees of UKBRs are not concerned regarding their job position/status. This is partly mitigated by the finding that most staff have similar job 
responsibilities, despite the existence of five broad levels of job position in the restaurants: manager, assistant manager, chef, waiter and stock delivery or kitchen assistant. Such positions tend to be for formal or documentation purposes, and in practice were often ignored for the purposes of efficiency and staff shortages. The study found that employees felt stressed because of their multiple job roles, as they have to finish different tasks in a strict schedule. For example,

'One of the chefs claimed that he is responsible for shopping, cooking, cleaning and other associated risks of health and safety issues. He is also responsible for the quality of food control. ' Nasir (R31, BR16, Waiter)

Shamsu (R24, BR12) is a waiter but he is involved in other tasks. For example, while there is staff shortage, he must do customer service and home delivery. He stated that:

'My job position is a waiter, and I do customer service, and sometimes I do home deliveries while staff shortage. So, I have to multi-task otherwise; I cannot continue my job in this restaurant.' (Shamsu, R24, BR12, Waiter)

\subsubsection{Employee retention}

Employee retention depends on many factors, such as pay, working life, JS, career progression, working environment and other benefits (Samuel and Chipunza, 2009). Of these, the most vital factors are good working life and JS. The long length of service is a positive sign for the organisation. However, employees coming and leaving jobs are undesirable for any organisation.

The data shows that long lengths of service are low in UKBRs. Most workers expressed an intention to leave their jobs within 1-12 months. The study found that low lengths of service were attributable to job dissatisfaction, poor payment, job pressure, verbal bullying, family issues, physical illness and undesirable working environments. Nasir (R31, BR16) explained that the:

'...coming and going' of employees is a continuous practice in the BRs.'

(Nasir, R31, BR16, Waiter)

\subsubsection{Pay and benefits}

Pay is, of course, a key direct financial benefit for working although non-financial benefits such as job autonomy, convenient working environment and an attractive workplace are also important motivations. However, the fieldwork revealed that it is an open secret amongst staff 
in UKBRs that their flat rates of payment, seldom meet the NMW. ${ }^{2}$ For example, Saiful, (R07, BR04), a Chef of a restaurant argued that:

'Most of the UKBRs did not follow pay rate according to government law.

They pay money per hour based on their perception. One important thing is that they do business in London, but at payment time they consider Bangladeshi currency per hour. This is their mentality. I get $£ 45$ per day which is less than NMW.' (Saiful, R07, BR04, Chef)

Wright and Pollert (2006) explain that 'tips' from customers have traditionally made up a significant part of wages for waiters and waitresses, compensating for low wages and contributing to a worker's sense that they can increase what they earn by working hard and providing good service. Additionally, the data of this study reveals that owners of the UKBRs does not share tips with the staff. However, employees benefitted from fringe benefits that included free meals, free accommodation and uniforms, and thus reducing the employees' living costs.

\subsubsection{Health and safety issues}

The fieldwork found the business owners to be attentive to health and safety issues for customers rather than workers. Thus, owners focused on the tidiness, cleanliness, interior design, air conditioning and facilities of the front of house (public areas) of the restaurants, while the back of house (kitchen and storeroom) was tended to be ignored. Occasional visits from local council health inspectors were important in terms of regulating the environmental health and working conditions of the restaurants, and required some paper documentation on health and safety practices. However, these have little or no relation to employees' realities.

Wright and Pollert (2006) found that training in restaurants was minimal, usually only in basic health and safety, hygiene or fire procedures. In some hotels, however, managers had recognised the neglect of training in the past and were offering staff the chance to pursue National Vocational Qualifications. The findings in BRs tended to confirm these results. There was evidence of poor levels of health and safety consciousness and widespread ignorance of formal health and safety training opportunities. A waiter of BRs mentioned that:

\footnotetext{
${ }^{2}$ The year that the interviews took place, the NMW in the UK is $£ 7.20$ per hour for workers aged over 25 ; 66.70 for workers aged from $21-24 ; £ 5.30$ for workers aged $18-20$; $£ 3.87$ for under- $18 \mathrm{~s}$; and $£ 3.30$ for apprentices (Home Office, 2016). Owners, however, have no concerns regarding this practice.
} 
'25 per cent health and safety issue maintain'. (Nasir, R31, BR16, waiter).

\subsection{Model 2: restaurants performance model}

The model below shows that the factors contributing to the performance of UKBRS in both financial and non-financial terms. The relationship between them is presented in Figure 2.

Figure 2. Restaurants performance model.

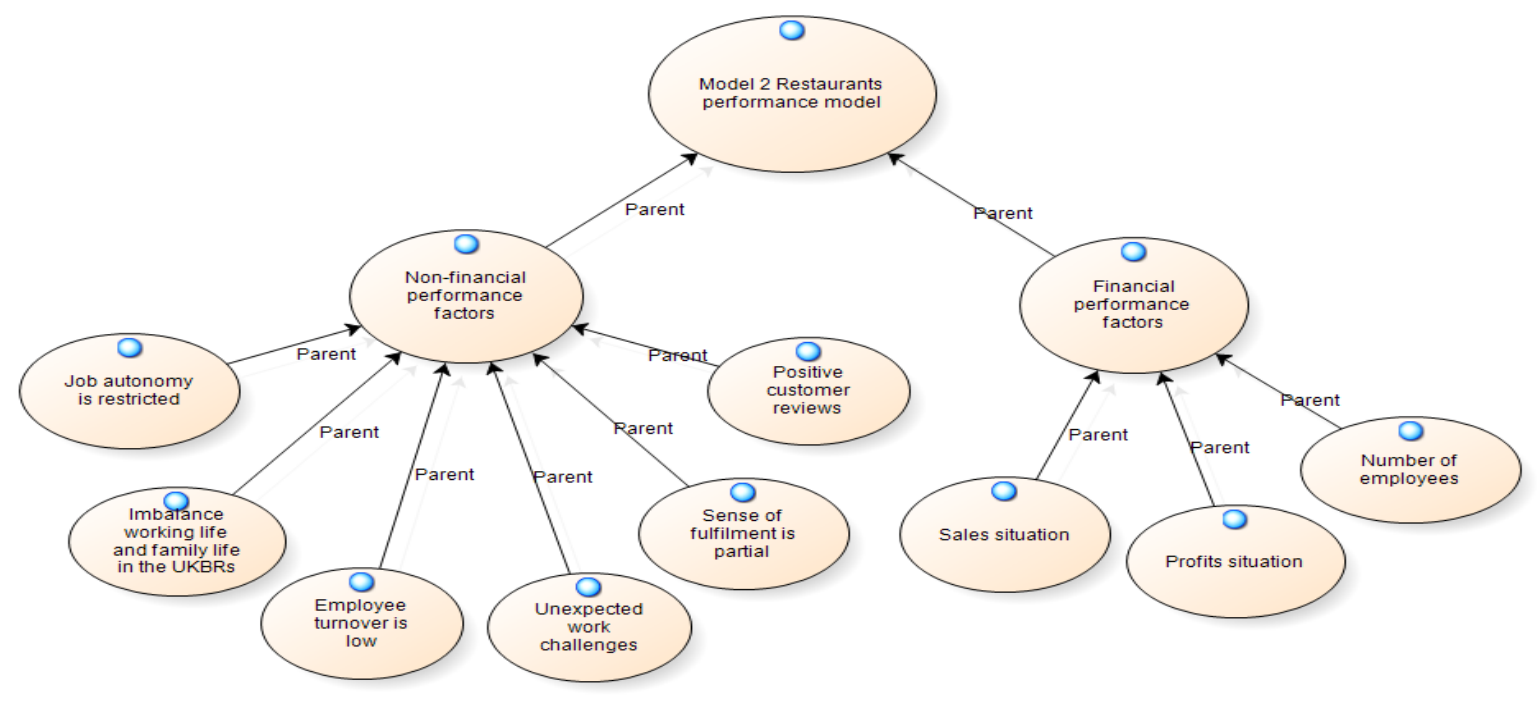

\subsubsection{Financial performance: UK Bangladeshi restaurants at downturn}

The primary research shows that both sales and profits in the interviewed restaurants have declined over the years. The key reasons appear to be a shortage of chefs, an unfavourable government policy for immigrants, and new entrants in this industry. A manager of a restaurant and a senior waiter of a restaurant stated, respectively:

'Now business is not okay. There is staff shortage due to the government's strict policy. Besides, more competitors have entered this market, for example, Turkish, Chinese and UK retail stores- Tesco's, Sainsbury's and Morrisons, etc. and they sell frozen foods that are cheaper than restaurant foods.' (Delwar, R40, BR20, Manager)

'Now, this is a big issue in the restaurant business environment as sales are down turning, but raw materials price is high and too many competitors have entered into this business. Thus, the business is negatively affected in sales and profits' (Nasir, R31, BR16, Waiter) 


\subsubsection{Non-financial performance factors}

\subsubsection{Job autonomy}

Job autonomy can take different forms, such as the freedom to set work schedules, priorities and patterns of work. Theories of job autonomy posit that employees are motivated by it and this leads them to improve their productivity. Employees with a good level of job autonomy are thus more committed, work harder, perform better, and there is a lower level of employee turnover. Thompson and Prottas (2006) indicate that job autonomy and informal organisational support are associated with almost all the above outcomes. Nguyen et al. (2003) explain that perceived job autonomy is found to be a highly significant determinant of five separate domains of JS: pay, fringe benefits, promotion prospects, job security and challenge of work. Morgeson et al. (2005) state that job autonomy, cognitive ability, and job-related skill were positively related to role breadth.

Our data on BRs shows that $58 \%$ of employees said they have some job autonomy. On the other hand, $42 \%$ of employees stated that they had no job autonomy at all, as they must follow their boss's orders without any flexibility.

\subsubsection{EWL UKBRS}

It is clear from the literature that a well-balanced working and family life is important for the productivity and performance of employees. Establishing such a balance for employees should be an institutional concern for employers, as it has an impact on overall organisational performance. The key focus of this investigation is to understand the relationship between EWL and performance in UKBRs. The research found several participants struggled to balance work life and family life. For example, a Chef explained his working life in the BR that:

'Balancing between family life and job life is tough because I finish my job late night and I cannot see my children. In the morning time, I sleep while my Child goes to school and I start my shift when my child comes home from school...' (Hamed, R39, BR20, Chef)

The fieldwork also found that some of the married workers had personal problems because they were unable to manage time for wives and children. However, part-time workers faced less difficulty.

The research data of this study shows that $55 \%$ of employees said they faced difficulty balancing work life and family life, while $45 \%$ of respondents indicated that they could balance 
working life. Overall, it demonstrates that achieving a satisfactory work life balance is particularly difficult in this sector. This has an adverse impact on EWL and performance.

\subsubsection{Employee turnover}

This research finds that employee turnover is a common issue in the UKBR sectors because of poor payment, long shift hours, weak promotional prospects, no social life and owners' domineering attitudes. Moreover, workers are restricted from joining trade unions. This dissatisfaction did not necessarily manifest itself in employee turnover. Some of the participants indicated that employee turnover is low because they have limited job opportunities. A restaurant manager stated:

'About employee turnover; the lower level staffs such as kitchen assistants leave their jobs because they want to go to the next position as a chef but it is difficult because that position is taken. So, they have to move elsewhere to get a good [job] opportunity and promotion.' (Belal, R35, BR18, Manager)

Overall, the primary data demonstrates that $24 \%$ participants said employee turnover is high, while $76 \%$ said that staff turnover is low. The key reason is an owner's 'trap strategy' to catch and keep them as employees for a long time without having opportunities to develop communication skills, education and training that they would need to move out of this sector into better employment.

\subsubsection{Work challenges}

Restaurant work has certain common challenges in dealing with individual customers' different levels of expectation of service. This research discovered some additional challenges in the job. For example, visitors from non-English countries who have different expectations and find it difficult to express their needs in English can generate specific challenges. One respondent, a waitress, explains that every job has some challenges, and she finds customers from European countries, who cannot speak English, particularly difficult ones to manage. However, she manages to deal with them politely, but it does affect her job performance and even psychologically. One of the assistant managers replied that:

'Every job has some challenges. We get it especially from European customers as they cannot speak English properly. However, we have to 
manage. But it is a challenge for us to understand them and what they are

looking for.' (Ibrahim, R27, BR14, Assistant Manager)

Moreover, in some cases, inebriated customers enter the restaurants late at night and create some problems, but owners are not interested in calling the police in case business is affected. Hence, workers have to manage drunk customers beyond their capabilities to satisfy owners. The primary data reveals that $83 \%$ respondents stated that they faced challenges in their job, while $17 \%$ said that they did not get any challenge in their job.

\subsubsection{Sense of fulfilment}

The research sought to explore the sense of fulfilment of employees in UKBRs, as this is crucial to their working life. The fieldwork found that although some workers are satisfied to some extent, some were unhappy. Thus, they lack a sense of fulfilment, has an adverse impact on their personal performance, as well as organisational performance (Gray et al., 2012). One of the respondents explained that he is satisfied with his job and has a sense of fulfilment. He gave his opinions:

I am satisfied with my job and have a sense of fulfilment because of the good atmosphere, good colleagues and customers. I am happy as I have job freedom and can manage my family life and work life.' (Tareq, R22, BR11, Waiter)

However, another waiter felt differently, explaining that he is not happy in this job. He added some points that:

'I am not happy in this job because of difficulty working till midnight which

affects my personal and family life. I am not truly happy, and my sense of fulfilment is zero.' (Nasir, R31, BR16, Waiter)

The findings of this research indicate that workers in UKBRs are fairly split about a sense of fulfilment. The primary data shows that $55 \%$ have a sense of fulfilment, while $45 \%$ had no sense of fulfilment.

\subsection{Theoretical and practical implications}

\subsubsection{Implications for theory}

The findings of this research provide a distinctive environment that raises questions regarding dominant theories on the relationship EWL and job performance. Generally, the outcomes of 
this study support the existing literature of EWL (e.g. Truss et al., 2006; Laar et al., 2007; Sivapragasam and Raya, 2014) and performance (e.g. Walker and Brown 2004; Gray et al., 2012). However, although these employees have mixed EWL experiences, the restaurants in which they work continue to survive. This suggests that generalisations about the relationship between EWL and performance require qualification. In this case, we raise the importance of the industry specific context and consideration for the religio-cultural background of those employed. This research contributes to the dominant theoretical assumptions in three ways.

First, it has provided a unique setting for an analysis of EWL and performance. It finds that this relationship subject to specific influences that are not taken into account in the general literature. They also vary within UKBRs. Second, the research shows that the context of the working life of the BR is beyond the mainstream UK literature, a specific context that is not explored in the general literature. Third, the study presents the idea of a 'Trap Strategy' by employers (i.e. employers constrain employees to develop their skills for mobility to other industries) rather than positive HR strategies in the UKBRs. This may or may not be conscious by owner-managers but is inevitably influenced the context of a declining small firm (restaurant) niche that has disempowered employees. In this regard, there is no evidence in the general literature. Thus, the findings have made a theoretical contribution to the knowledge management.

\subsubsection{Implications for practice}

The research develops two empirical models that are useful for practice. The models have set out the main factors that influence the working lives of employees in BRs. This may be used to help owner-managers develop their human resource management practices, improve the working lives of employees and ultimately the performance of their businesses. Second, the model can benefit other ethnic minority businesses such as the Turkish and Chinese communities in the UK. Finally, the findings can be of benefit to academics, practitioners and policy makers of EMBs in the UK and other countries.

For generalizability, a large-scale questionnaire study is needed for statistically significance and to validate any generalisations. The research is also limited in its geographical scope. However, the generalisation of its findings to broader groups may be difficult because of different contexts: economic conditions, cultures, religious beliefs and job circumstances. 


\section{Conclusions}

Bangladeshi-owned enterprises make up a significant proportion of EMB business population. A significant portion of these are in the food sector, including restaurants, catering and 'takeaways'. This sector has experienced rapid growth but more recently, some decline (Alexander et al., 2020). While there has been academic research into EMBs, there has been an insufficient focus on Bangladeshi business and especially the working life of employees in these enterprises. Therefore, this paper combines a focus on EWL and performance in BRs located in the UK. It has developed contextually embedded empirical models that highlight the factors that first shape EWL in Bangladeshi restaurants and second, their business performance. In particular, the aim of this paper has been to examine and present the linking between employees' working life and performance of UK ethnic minority restaurants. To achieve this, this study set out two research aims. The first was to investigate the relationship between EWL and performance in BRs in the UK. The second was to establish the relationship between EWL and restaurant performance, with particular reference to non-financial performance.

Two key top-level themes emerged from the analysis of the empirical data of 40 indepth interviews, each of which highlighted a particular aspect of the relationship between EWL and performance in BRs. To this end, we developed two empirical models that derived from the two themes. Each model explores some key issues for EWL and the performance of firms in the BRs sector. Although our findings show a link between EWL and performance, supporting previous empirical literature, we also highlight some differences that may be important to understand the link between EWL and performance in BRs.

For example, through this paper, the key contributors to non-financial performance identified in the literature is in contrast with the situation found in primary research data on UKBRs. First, previous research shows that employee job autonomy and a sense of fulfilment are the key non-financial performance factors in small firms; however, this paper shows that, in BRs, job autonomy is restricted, and employees have only a partial sense of fulfilment. Second, the existing research also finds that job challenges and the prospects of career advancement lead to improved performance. However, our findings show that EWL in UKBRs are characterised by multiple job challenges, and uncertainty of career and career progress, resulting in poor performance in the BRs. Third, the review of literature shows that a good work-life balance and consistent working conditions improve the performance of organisations (Hyman and Summers, 2007; Turner et al. 2009; Murphy and Doherty, 2011). Moreover, work life programmes are positively associated with performance (Soomro et al., 2018; Akter et al., 2019). Nevertheless, we find that in UKBRs workers find it hard to balance work and family 
life, and have to work in unhealthy working conditions, which negatively affects their performance. Overall, therefore, our data shows that UKBRs demonstrate few of the elements of EWL that contribute to a strong non-financial performance on the part of the business.

Further research into the linking between EWL and financial performance could also add value to the findings of this study. The results are based on 40 face-to-face in-depth interviews and supplemented with secondary sources. These results, therefore, are not generalizable across all BRs or SMEs in the UK. However, the depth of the interviews provides insights into the condition of the working life in BRs and the reasons for this condition. These are unique and significant in terms of helping understand the working lives of employees in BRs. It is suggested that a large-scale questionnaire study is undertaken if statistical generalisability is required. This research has also been limited in its geographical scope. The research studied EWL and performance in BRs in Greater London in the UK. However, it may be useful to replicate this study in other countries with diverse economic status, cultures and religions. Finally, the analysis could be extended to other restaurant types in the UK. To what extent are these findings a result of the sector in which the firms operate or a result of ethnic group and contextual factors? 


\section{References}

Allam, Z. and Shaik, A., (2020). A study on quality of work life amongst employees working in the Kingdom of Saudi Arabia, Management Science Letters, 10(6), pp.1287-1294.

Akehurst, G., Comeche, J. M. and Galindo, M. A. (2009). Job satisfaction and commitment in the entrepreneurial SME, Small Business Economics, 32(3), pp. 277-289.

Akter, K., Ali, M. and Chang, A. (2019). Work-life programmes and organisational outcomes: the role of the human resource system, Personnel Review, 49(2), pp. 516-536.

Alves, P., Bouquin, S. and Pocas, L. (2007). Working time in European SMEs, European Review of Labour and Research, 13(75), pp. 74-93.

Alexander, C., Carey, S., Hall, S., King, J., and Lidher, S. (2020). Beyond Banglatown: continuity, change and new urban economies in Brick Lane. Runnymede Trust, London.

Alrawadieh, Z., Cetin, G., Dincer, M.Z. and Istanbullu Dincer, F. (2020). The impact of emotional dissonance on quality of work life and life satisfaction of tour guides, The Service Industries Journal, 40(1-2), pp.50-64.

Angel, P., Jenkins, A., and Stephens, A. (2018). Understanding entrepreneurial success: A phenomenographic approach. International Small Business Journal, 36(6), pp. 611-636.

Anvaria, R., Jian, F. Z. and Chermahinic, S. H. (2013). Effective strategy for solving voluntary turnover problem among employees, International Conference on Innovation, Management and Technology Research, Malaysia, pp. 22-23.

Atkinson, J. (1984). Manpower strategies for flexible organisations, Personnel Management, pp. 28-31.

Bakker, A.B. and Oerlemans, W. (2011). Subjective well-being in organizations, in Cameron, K.S. and Spreitzer, G.M. (Eds), The Oxford Handbook of Positive Organizational Scholarship, Oxford University Press, New York, NY, pp. 178-89.

Basu, A. and Altinay, E. (2002). The interaction between culture and entrepreneurship in London's immigrant businesses, International Small Business Journal. 20(4), pp. 371-93.

Blackburn, R. A., Hart, M. and Wainwright, T. (2013). Small business performance: business, strategy and owner-manager characteristics, Journal of Small Business and Enterprise Development, 20(1), pp. 8-27.

Bloch, A. and McKay, S. (2015). Employment, social networks and undocumented migrants: The employer perspective, Sociology, 49(1), pp.38-55.

Birrell, I. (2015). Curry house crisis as two shut every week: Hundreds of popular restaurants face closure due to a crippling shortage of chefs, Daily Mail, 23 August [Online]. Available at: http://www.dailymail.co.uk/news/article-3207466/Curry-house-crisis-two-shut-week-

Hundreds-popular-restaurants-face-closure-crippling-shortage-chefs.html (Accessed: 19 July 2016).

Boonlua, S. and Aditto, S. (2013). Factors influencing among the small and medium enterprises (SMEs) in Laos, Journal of International Business \& Economics, 13(3), pp. 33-42.

Bozeman, B. and Gaughan, M. (2011). Job satisfaction among University Faculty: individual, work, and institutional determinants, The Journal of Higher Education, 80(6), pp. 154-186.

Bozionelos, N. and Singh, S. K. (2017). The relationship of emotional intelligence with task and contextual performance: More than it meets the linear eye, Personality and Individual Differences, 116, 1, pp. 206-211. 
Braun, V. and Clarke, V. (2006). Using thematic analysis in psychology, Qualitative Research in Psychology, 3, pp.77-101.

Bryman, A. and Bell, E. (2011). Business Research Methods, 3rd edn. New York: Oxford University Press.

Budhwar, P., Pereira, V., Mellahi, K. and Singh, S.K., (2019). The state of HRM in the Middle East: Challenges and future research agenda, Asia Pacific Journal of Management, 36(4), pp. 905-933.

Buhai, S., Cottini, E. and Westergaard-Nielsen, N. (2008). The impact of workplace conditions on firm performance, Working Papers 08-13, University of Aarhus, Aarhus School of Business, Department of Economics.

Burke, R.J. and McAteer, T. (2007). Work hours and work addiction: The price of all work and no play, Research in Occupational Stress and Wellbeing, 6, pp.239-273.

Connell, J. and Hannif, Z. (2009). Call centres, quality of work life and HRM practices, Employee Relations, 31(4), pp. 363-381

Corby, S. and White, G. (1999). Employee relations in the public services themes and issues, London: Routledge.

Dhamija, P., Gupta, S. and Bag, S. (2019). Measuring of job satisfaction: the use of quality of work life factors, Benchmarking: An International Journal, 26(3), pp. 871-892.

Deery, M. and Jago, L. (2008). A framework for work - life balance practices: Addressing the needs of the tourism industry, Tourism and Hospitality Research, 9(2), pp. 97-108.

Deloitte (2017). At a Tipping Point? Workplace Mental Health and Wellbeing, Deloitte Centre for Health Solutions, London.

Department for Business Innovation and Skills (2020). Business population estimates for the UK and regions 2020: statistical release Published 8 October 2020. Available at: https://www.gov.uk/government/statistics/business-population-estimates-2020/business-

population-estimates-for-the-uk-and-regions-2020-statistical-release-html\#headline-statistics (Accessed: 20 February 2021).

Department of Trade and Industry (2004). Britain's workers crave more time with friends in 2004 [Online]. Available at: http://164.36.164.20/work-lifebalance/press_2704a.html (Accessed: 15 November 2013).

Dex, S. and Scheibl, F. (2001). Flexible and family-friendly working arrangements in UKbased SMEs: Business Cases, British Journal of Industrial Relations, 39(3), pp. 411-431.

Dhir, S. and Shukla, A. (2019). Role of organizational image in employee engagement and performance, Benchmarking: An International Journal, 26(3), pp. 971-989.

Foy, T., Dwyer, R.J., Nafarrete, R., Hammoud, M.S.S. and Rockett, P. (2019). Managing job performance, social support and work-life conflict to reduce workplace stress, International Journal of Productivity and Performance Management, 68(6), pp. 1018-1041

Gillan, A. (2002). From Bangladesh to Brick Lane, the Guardian, 21 April [Online]. Available at: http://www.theguardian.com/uk/2002/jun/21/religion.bangladesh (Accessed: 22 April, 2014)

Gray, D., Saunders, M. and Goregaokar, H. (2012). Success in challenging times: Key lessons from $U K$ [Online]. Available at: 
https://www.surrey.ac.uk/sbs/files/Success_in_Challenging_Times_Report\%20.pdf (Accessed: $1^{\text {st }}$ January 2014).

Guilding, C., Lamminmaki, D., \& McManus, L. (2014). Staff turnover costs: In search of accountability, International Journal of Hospitality Management, 36, pp. 231-243.

Gupta, M., Shaheen, M. and Das, M. (2019). Engaging employees for quality of life: mediation by psychological capital, The Service Industries Journal, 39(5-6), pp.403-419.

Han, S.J., Kim, W.G. and Kang, S. (2017). Effect of restaurant manager emotional intelligence and support on front-of-house employees' job satisfaction, International Journal of Contemporary Hospitality Management, 29(11), pp. 2807-2825.

Hasle, P., Limborg, H. J., Kallehave, T., Klitgaard, C. and Andersen, T. R. (2011). The working environment in small firms: responses from owner-managers, International Small Business Journal, 30(6), pp. 622-639.

Haq, M., (2015) 'South Asian ethnic minority small and medium enterprises in the UK: a review and research agenda', International Journal of Entrepreneurship and Small Business, 25(4), pp.494-516.

Home Office (2016) 'National minimum wage'. Available at: https://www.gov.uk/nationalminimum-wage-rates (Accessed: 24 August, 2016).

Harney, B., \& Alkhalaf, H. (2020). A quarter-century review of HRM in small and mediumsized enterprises: Capturing what we know, exploring where we need to go. Human Resource Management, 60(1), pp. 5-30.

Hyman, J., Baldry, C., Scholarios, D and Bunzel D. (2003). Work-life imbalance in call centres and software development, British Journal of Industrial Relations, 41(2), pp.215-39.

Ingham, G. (1970). Size of Industrial Organization and Worker Behaviour. Cambridge University Press, Cambridge.

Judge, T. A. and Watanabe, S. (1993). Another look at the job satisfaction-life satisfaction relationship, Journal of Applied Psychology, 78(6), pp.939-948.

Jung, H.S. and Yoon, H.H. (2019). How does workplace harassment influence the employees' response in a deluxe hotel?, The Service Industries Journal, 39(11-12), pp.877-900.

Kakkar, S., Dash, S., Vohra, N. and Saha, S. (2020). Engaging employees through effective performance management: an empirical examination, Benchmarking: An International Journal, 27(5), pp. 1843-1860.

Kalleberg, A. L. (2001). Organizing flexibility: the flexible firm in a new century, British Journal of Industrial Relations, 39(4), pp.479-504.

Kansas State University (2009, February 4) 'Happy employees are critical for an organization's success', Study Shows. Science Daily. Retrieved November 19, 2013, from http://www.sciencedaily.com /releases/2009/02/090203142512.htm.

Keeman, A., Neaswall, K., Malinen, S. and Kuntz, J. (2017). Employee wellbeing: evaluating a wellbeing intervention in two settings, Frontiers in Psychology, 8, pp. 1-14.

Khan, R. (2020). The fight is on to save the great British curry from coronavirus. Independent [Online], 13 May 2020. Available from: https://www.independent.co.uk/voices/coronavirusbritish-curry-house-restaurant-bangladesh-awards-brexit-a9510391.html (accessed at 9th July 2020). 
Khandaker, P. (2016). Bangladesh Caterers Association UK, [Online]. Available at: http://www.bca1960.com/index.php/2012-08-22-16-56-48/about-bca.html (Accessed: 15 December 2013).

Khandaker, P. (2016). Bangladeshi curry house bosses call on voters to back Brexit to save thousands of restaurants from closing, Daily Mail, 26 May [Online]. Available at: http://www.dailymail.co.uk/news/article-3610331/Bangladeshi-curry-house-bosses-callvoters-Brexit-save-thousands-restaurants- closing.html\#ixzz4bhkkAFWf (Accessed 12 June 2016).

Khandaker, P. (2013). Bangladesh Caterers Association UK, [Online]. Available at: http://www.bca1960.com/index.php/2012-08-22-16-56-48/about-bca.html (Accessed: 15 December 2013)

Laar, D. V., Edwards, J. E. and and Easton, S. (2007). The work-related quality of life scale for healthcare workers, Journal of Advanced Nursing, 60(3), pp.325-333.

Lai, Y., Saridakis, G., Johnstone, S. (2017). Human resource practices, employee attitudes and small firm performance, International Small Business Journal, 35 (4). pp. 470-494.

Leiva, D., Sa'nchez-Vidalb, M. E., and Cegarra-Navarro, J. G. (2012). Work life balance and the retention of managers in Spanish SMEs, The International Journal of Human Resource Management, 23(1), pp. 91-108.

Lewis, D., Manolchev, C., Pursell, L., Hodgins, M., Hogan, V. and Mannix-McNamara, P. (2020). The SME paradox? Investigating ill-treatment behaviours in small and medium-sized enterprises in Ireland, International Small Business Journal, 38(8), pp. 746-767.

Liebregts, W. and Stam, E. (2019). Employment protection legislation and entrepreneurial activity, International Small Business Journal, 37(6), pp. 581-603.

Lin, C. Y (1998). Success factors of small- and medium-sized enterprises in Taiwan: An analysis of cases, Journal of Small Business Management; Milwaukee, 36(4), pp. 43-56.

Lomas-Farley, C. (2016). Curry Chef Shortage Creates Closure Crisis, Sky News, 4 July [Online]. Available at: http://news.sky.com/story/curry-chef-shortage-creates-closure-crisis10337862 (Accessed: 19 July 2016)

McGaughey, R., Puleo, V. and Casey, K.M. (2005). Employee benefits of multi-owner accounting firms: groundwork for benchmarking, Benchmarking: An International Journal, 12 (4), pp. 354-363.

Mahrouq, M. (2010). Success factors of small and medium-sized enterprises (SMEs): the case of Jordan, Anadolu University Journal of Social Sciences, 10(1), pp. 1-16.

McFadyen, S. (2015). Curry crisis as two Indian restaurants a week are closing down as skills shortage bites, Daily Mirror, 24 August [Online]. Available at: http://www.mirror.co.uk/news/uk-news/curry-crisis-two-indian-restaurants-6309893 (Accessed: 19 July 2016).

Mathisen, G.E., Einarsen, S. and Mykletun, R., (2008). The occurrences and correlates of bullying and harassment in the restaurant sector. Scandinavian Journal of Psychology, 49(1), pp.59-68.

Maslach, C. Schaufelli, W.B. and Leiter, M.P. (2001). Job burnout, Annual Review of Psychology, 52, pp. 397-422. 
Messersmith JG, Patel PC, Crawford C. (2018). Bang for the buck: Understanding employee benefit allocations and new venture survival, International Small Business Journal, 36(1), pp. 104-125.

Morgeson, F. P., Delaney-Klinger, K. and Hemingway, M. A. (2005). The importance of job autonomy, cognitive ability, and job-related skill for predicting role breadth and job performance, Journal of Applied Psychology, 90(2), pp. 399-406.

Murphy, F. and Doherty, L. (2011). The experience of work life balance for Irish senior managers, Equality, Diversity and Inclusion: An International Journal, 30(4), pp. 252-277.

Naseem, A., Sheikh, S.E. and Malik, K.P. (2011). Impact of employee satisfaction on success of organization: relation between customer experience and employee satisfaction, International Journal of Multidisciplinary Sciences and Engineering, 2(5), pp. 41-46.

Nguyen, A. N., Taylor, J., and Bradley, S. (2003). Job autonomy and job satisfaction: New evidence (Working Paper 2003/050). Lancaster, England: Management School, Lancaster University.

Nguyen, A., Taylor, J. and Bradley, S. (2003). Relative pay and job satisfaction: some new evidence [Online]. Available at: https://mpra.ub.unimuenchen.de/1382/1/MPRA_paper_1382.pdf (Accessed at $1^{\text {st }}$ January 2017).

Ogunyomi, P. and Bruning, N. S. (2016). Human resource management and organizational performance of small and medium enterprises (SMEs) in Nigeria, The International Journal of Human Resource Management, 27(6), pp.612-634.

Olugbade, O.A. and Karatepe, O.M. (2019). Stressors, work engagement and their effects on hotel employee outcomes. The Service Industries Journal, 39(3-4), pp.279-298.

Pajo, K., Coetzer, A. and Guenole, N. (2010). Formal development opportunities and withdrawal behaviors by employees in small and medium-sized enterprises, Journal of Small Business Management, 48(3), pp. 281-301.

Pedaci, M. and Betti, M. (2020). The Regulation of Employment Relationships at the Enterprise. In Regalia, I. (Ed.) Regulating Work in Small Firms (Ch. 4 pp. 131-163). Palgrave Macmillan, Cham.

Quinlan, C. (2011). Business Research Methods. United Kingdom: South-Western Cengage Learning.

Ram, M., Sanghera, B., Abbas, T., Barlow, G. and Jones, T. (2000). Ethnic minority business in comparative perspective: the case of the independent restaurant sector, Journal of Ethnic and Migration Studies, 26(3), pp. 495-510.

Ram, M., Edwards, P. and Jones, T. (2007). Staying underground: informal work, small firms, and employment regulation in the United Kingdom, Work and Occupations, 34(3), pp. 318344.

Ram, M. and Jones, T. (2008). Ethnic minority businesses in the UK: An overview, in Oliveira, C.R. and Rath, J. (eds.), Migrações Journal - Special Issue on Immigrant Entrepreneurship, n. 3, Lisbon: ACIDI, pp. 61-71.

Rainnie, A. (1989). Industrial Relations in Small Firms, London: Routledge.

Robson, C. (2011). Real world research. $3^{\text {rd }}$ end. London: A John Wiley and Sons, Ltd.

Samuel, M.O. and Chipunza, C. (2009). Employee retention and turnover: Using motivational variables as a panacea, African journal of business management, 3(9), p.410. 
Saridakis, G, Lai, Y., Muñoz Torres, R. I., Gourlay, S. (2020). Exploring the relationship between job satisfaction and organizational commitment: an instrumental variable approach, The International Journal of Human Resource Management, 31(13). pp. 1739-1769.

Saridakis, G. and Cooper, C. L. (2016). Research handbook on employee turnover. New Horizons in Management Series, Edward Elgar Publishing Limited, Cheltenham. UK.

Saridakis, George, Muñoz Torres, Rebeca, Johnstone, Stewart (2013). Do Human Resource Practices Enhance Organizational Commitment in SMEs with Low Employee Satisfaction? British Journal of Management, 24 (3), pp. 445-458.

Saunders, M., Lewis, P. and Thornhill, A. (2009). Research methods for business students, $5^{\text {th }}$ edition. London: Financial Times/Prentice Hall.

Shanker, S., Sharma, H. and Barve, A. (2021). Assessment of risks associated with third-party logistics in restaurant supply chain, Benchmarking: An International Journal, Vol. ahead-ofprint No. ahead-of-print. https://doi.org/10.1108/BIJ-06-2020-0343.

Sheehan, M. (2014). Human resource management and performance: Evidence from small and medium-sized firms. International Small Business Journal, 32(5), pp. 545-570.

Simpson, M., Tuck, N. and Bellamy, S. (2004). Small business success factors: the role of education and training, Education + Training, 46(8/9), pp. 481-491.

Simons, T. and Enz, C.A., (1995). Motivating hotel employees: Beyond the carrot and the stick', Cornell Hotel and Restaurant Administration Quarterly, 36(1), pp. 20-27.

Singh, S.K. and Singh, A.P. (2019). Interplay of organizational justice, psychological empowerment, organizational citizenship behavior, and job satisfaction in the context of circular economy, Management Decision, 57(4), pp. 937-952.

Singh, S.K., Pradhan, R.K., Panigrahy, N.P. and Jena, L.K. (2019a). Self-efficacy and workplace well-being: moderating role of sustainability practices. Benchmarking: An International Journal, 26(6), pp. 1692-1708.

Singh, S.K., Mittal, S., Sengupta, A. and Pradhan, R.K. (2019b). A dual-pathway model of knowledge exchange: linking human and psychosocial capital with prosocial knowledge effectiveness, Journal of Knowledge Management, 23(5), pp. 889-914.

Sivapragasam, P. and Raya R. P. (2014). Exploring the Link between Job Quality and Employee Well-being: An Empirical Study, Asia-Pacific Journal of Management Research and Innovation, 10(4), pp. 267-77.

Shih, C.T., Chen, S.L. and Chao, M. (2019). How autonomy-supportive leaders influence employee service performance: a multilevel study, The Service Industries Journal, pp.1-22.

Sivapragasam, P. and Raya R. P. (2014). Exploring the Link between Job Quality and Employee Well-being: An Empirical Study, Asia-Pacific Journal of Management Research and Innovation, 10(4), pp. 267-77.

Skorstad, E. J. and Ramsdal, H. (2009). Flexible organisation and the new working life: A European perspective, Farmham: Ashgate Publishing Limited.

Soomro, A.A., Breitenecker, R.J. and Shah, S.A.M. (2018). Relation of work-life balance, work-family conflict, and family-work conflict with the employee performance-moderating role of job satisfaction, South Asian Journal of Business Studies, 7(1), pp. 129-146. 
Sobaih, A.E., Coleman, P., Ritchie, C. and Jones, E. (2011). Part-time restaurant employee perceptions of management practices: An empirical investigation, The Service Industries Journal, 31(11), pp.1749-1768.

Storey, D.J., Saridakis, G., Gupta, S.S., Edwards, P.K. and Blackburn, R. A. (2010). Linking HR formality with employee job quality: the role of firm and workplace size, Human Resource Management, 49(2), pp.305-329.

Thompson, C. A. and Prottas D. J. (2006). Relationships among organizational family support, job autonomy, perceived control, and employee well-being, Journal of occupational health psychology. 11(1), pp.100118.

Tang, C.H. and Lee, J.E. (2014). Employee satisfaction and long-run shareholder returns, The Service Industries Journal, 34(14), pp.1167-1183.

Turner, M., Lingard, H. and Francis, V. (2009). Work-life balance: an exploratory study of supports and barriers in a construction project, International Journal of Managing Projects in Business, 2(1), pp.94-111.

Truss, K., E. Soane, C. Edwards, K. Wisdom, A. Croll and J. Burnett (2006). Working life: employee attitudes and engagement. London: CIPD.

Tuzovic, S. and Kabadayi, S. (2021). The influence of social distancing on employee wellbeing: a conceptual framework and research agenda, Journal of Service Management, 32(2), pp. 145-160.

Van Landuyt, Y., Dewaelheyns, N. and Van Hulle, C. (2017). Employment protection legislation and SME performance, International Small Business Journal, 35(3), pp. 306-326.

Vliet, C. and Hellgren, J. (2002). The modern working life: Its impact on employee attitudes, performance and health, Department of Psychology, Stockholm University, Report No 4:2002, SALTSA.

Wach, D., Stephan, U. and Gorgievski, M. (2016). More than money: Developing an integrative multi-factorial measure of entrepreneurial success, International Small Business Journal, 34(8), pp.1098-1121.

Walker, E. and Brown, A. (2004). What success factors are important to small business owners?' International Small Business Journal, 22(6), pp. 577-594.

Wilkinson, A. (1999). Employment relations in SMEs', Employee Relations, 21(3), pp.206217.

Wilson, B. (2017). Who killed the curry house? Why has Britain turned its back on its favourite food and shut out the people needed to cook it, The Guardian, 12 January, p. 29.

Witts, S. (2015). Chef shortage closing crisis for UK curry restaurant [Online]. Available at: http://www.bighospitality.co.uk/Trends-Reports/Chef-shortage-causing-crisis-for-UK-curryrestaurants (Accessed: 19 July 2016).

Wright, T. and Pollert, A. (2006). The experience of ethnic minority workers in the hotel and catering industry: Routes to support and advice on workplace problems [Online]. Available at: http://www.acas.org.uk/media/pdf/0/b/03-06_1.pdf (Accessed: 9 December 2015).

Yang, Y., Liu, H. and Chen, X. (2020). COVID-19 and restaurant demand: early effects of the pandemic and stay-at-home orders, International Journal of Contemporary Hospitality Management, 32(12), pp. 3809-3834. 